\title{
Montañas y sujetos: un acercamiento teórico a las huellas simbólicas del montañismo en el universo social y cultural
}

\author{
Patricio Javier Aguirre Negrete
}

RESUMEN:

El MONTAÑISMo REPRESENTA UNA DE LAS ACTIVIDADES MÁS EXTRAÑAS Y RIESGOSAS QUE HA EMPRENDIDO EL SER hUMANO. DESDE UNA MIRAda TEÓRICA, EN LA QUE ENTRAN EN JUEGo LA CULTURA, EL PODER Y LA SIGNIFICACIÓN, EL MONTAÑISMO DEVELA CIERTOS ASPECTOS SIMBÓLICOS DE LOS IMAGINARIOS SAGRADOS, LA VISIÓN DEL MUNDO QUE COMPRENDE LA CONSTITUCIÓN DEL SUJETO MONTAÑISTA, ASÍ COMO LAS CONSTRUCCIONES SOCIALES QUE BORDEAN ESTA ACTIVIDAD.

Palabras Clave: montaña - SuJeto - Símbolo - SACRAlidad - JUego - Sentido

\section{Abstract}

MountaIneERING REPRESENTS ONE OF THE MOST BIZARRE AND RISKY ACTIVITIES UNDERTAKEN BY hUMANS. From A THEORETICAL PERSPECTIVE, IN WHICH PLAY, CULTURE, POWER AND SIGNIFICANCE COME INTO PLAY, MOUNTAINEERING UNVEILS SYMBOLIC ASPECTS OF SACRED IMAGINATIONS, MOUNTAINEERS' VISION OF THE WORLD, AS WELL AS THE SOCIAL CONSTRUCTIONS THAT SURROUND THIS ACTIVITY.

KEY wORdS: MounTAIN - SUBJECT - SYMBOL - SACREDNESS - GAME - SIGNIFICANCE/SENSE

1 Antropólogo, Pontificia Universidad Católica del Ecuador, Facultad de Ciencias Humanas. Candidato a Magíster en Estudios de la Cultura con mención en Literatura Hispanoamericana, Universidad Andina Simón Bolívar, Área de Letras. Corre electrónico: pjaguirren@hotmail.com paguirrenegrete@gmail.com 


\section{Hacia una mirada antropológica del montañismo}

$\mathrm{E}$

n un esfuerzo por indagar los sentidos inmersos en las construcciones simbólicas y sociales del andinismo en el Ecuador, se planteó identificar y analizar principalmente los significados enraizados en el(los) sujeto(s) montañista(s) con respecto a la cumbre -o vía de ascensión- de una montaña. A partir de un corpus teórico delineado por lo sagrado, el cauce de la investigación devino en una suerte de cartografía determinada por un centro inamovible: todas las líneas, relieves, cuadrillas convergen en un mismo punto: subir una montaña implica más el reflejo de la fijación del individuo por habitar ciertos lugares que se le presentan como inhabitables, que la búsqueda de una trascendencia. Se halló que esta fijación comprende una serie de elementos simbólicos que otorgan "poder", "autoridad", "reconocimiento" al sujeto andinista, el cual utiliza la ascensión como referente simbólico para validar ciertas características de divinización y de heroicidad; pero, sobre todo, permitió una reflexión (la cual bien puede o no ser vista como válida) de tintes holísticos en la cual se devela que los sentidos y significados insistentes de los individuos montañistas -de subir una montaña-, representa finalmente una extensión de la voluntad humana, o bien de la cultura, por llegar, culturizar, domesticar esos espacios en los que la supervivencia o la estadía del organismo humano por un tiempo prolongado, se torna imposible. El ejemplo principal de este hallazgo fueron los registros de ascensión: retratos, fotografías, relatos, todos proyectados como esa manera de asir lo inasible. Es decir, si no se puede domesticar, culturizar la cumbre de una alta montaña, está el imaginario para capturarla. Vale decir que el presente artículo responde solamente a la sección teórica de esta investigación, se intenta poner en diálogo diversas fuentes que puedan dar fondo y forma a este mundo simbólico tan poco atendido por las ciencias sociales.

\section{Significación y cultura}

El ser humano teje su universo a partir de significaciones y sentidos. Confiere al mundo y por ende a sí mismo las formas imaginarias que moldean su visión y comportamiento. La cultura es, dentro de esta perspectiva, el escenario donde se diseminan e interactúan los caracteres semánticos por medio de una relación íntima, específica entre el significado y el signo. Esta relación, conocida bajo el término de representación, es una presencia inherente en el ser humano, inseparable de su constitución social, cultural, humana.

Siguiendo a Clifford Geertz (2003: 20), la cultura representa esa inmersión constante que lleva al ser humano a elaborar partituras de significación que funden su espacio y comportamiento. Desde allí que el concepto de cultura sea un componente esencialmente semiótico .

Este mismo autor considera al análisis de la cultura como una ciencia interpretativa, cuya característica primordial radicaría en sumergirse, adentrarse en constantes búsquedas de significaciones mientras su finalidad es la explicación de los elementos, sus expresiones e interacciones (Ibid.).

Tomando en consideración al estudio antropológico, siguiendo a Marc Augé (1987-77: 78), representa el compromiso de adentrarse al sentido íntimo, específico, expresivo de una sociedad. Tal estudio no haría sino reconocer, finalmente, la universalidad de la cultura en sus diversas manifestaciones, entendiendo que ninguna sociedad, por diferente que sea, está desprovista de sentido alguno. Augé alude, afianza, retrata la universalidad de lo humano presente en todas sus expresiones, su componente íntimo es el componente significativo asignado a un elemento social en juego, sentido que toda su estructura cultural comparte .

Tanto Augé como Geertz intervienen desde un mismo fulcro imprescindible en su propuesta etnológica: los símbolos. Es entorno a la simbología que los componentes semánticos toman forma en base a la fuerza de representación que poseen los elementos simbólicos. Es de esta 
manera que Geertz (2003)define al esfuerzo interpretativo de la cultura como el "análisis de sistemas de interacción de símbolos" (Ibid.: 27).

La cultura en tal consecuencia conceptual no podría ser simplificada como una entidad, o bien como un conjunto de instituciones reguladoras o procesos sociales. El análisis pertinente de la cultura no sería sino el de englobar, contextualizar y analizar todos sus aspectos constitutivos, sus fenómenos y representaciones de manera inteligible, exhaustiva; en palabras de Geertz: "densa" (Ibid.).

La construcción simbólica de una sociedad específica, desde la reflexión teórica de Augé (1987), no podría reducirse a determinarla como una expresión propia, nativa, cercando una diferencia tajante entre un adentro y la observación alejada, ajena, que instaura un "afuera". Tal posición conduciría, a quien la analiza, hacia una interpretación especular del simbolismo. Lo que entiende Augé es el hecho y la importancia de conducir el estudio al sentido íntimo y específico que la sociedad en cuestión constituye, "susceptible de diversificarse en múltiples relaciones de significación y restricción” (Ibid.: 77-78).

La cultura, dentro de estos términos, sería entonces esa urdimbre de componentes simbólicos en constante interacción, donde cada sociedad establece sus espacios propios, sus centros y significados. La cultura es esa trama compleja de sistemas simbólicos donde el ser humano se desenvuelve potenciando su ser social y cultural. Es un documento activo, público, en el cual se afirma la conducta humana como acción simbólica, en su universalidad de diversas manifestaciones representativas; como menciona Geertz (2003: 25): "la cultura es pública porque la significación lo es".

\section{El símbolo y la representación}

La huella principal del mundo simbólico está sostenida por su función representativa. Dicha función se ha establecido en el universo sociocultural como un escenario de comunicación e identificación. Los símbolos, como sustenta Elias (1994: 171), "son medios de orientación, comunicación y formas de pensamiento", están entretejidos en los límites del entorno social, atravesándolo, fijando sus partes como un lienzo que "lo abarca todo, lo mismo que el espacio y el tiempo" (Ibid.:153).

El mundo simbólico y el espacio social se manifiestan claramente en la regularización social. Según Elias (1994: 35) tal regularización se define cuando los miembros de una misma sociedad identifican las mismas pautas sonoras (fonemas en interconexión) con el mismo sentido correspondiente, de manera que los símbolos representan el objeto de conocimiento al cual se están refiriendo.

Un símbolo en particular tiene una carga de significación común para quienes lo emplean. El sentido, de esta manera, es atribuido en un sistema de reconocimiento social donde el "significado de una acción para el actor está co-determinado, como norma, por el significado que puede tener para otros" (Ibid.: 93). Todo debe ser captado desde el lugar en el que se pronuncia y el lugar al que se dirige, como puntadas que entrelazan los elementos de la interacción y la aprehensión en la vida social. Como bien declara Garagalza (2002): "Por símbolo ha de entenderse aquí toda energía del espíritu en cuya virtud un contenido espiritual de significado es vinculado a un signo sensible concreto y le es atribuido interiormente" (Ibid.: 72).

El universo simbólico nos atraviesa, nos compone plenamente; se integra al mundo real dotándole de formas significativas duales en constante movimiento y diversificación. Garagalza lo define como una irrupción, un resquebrajamiento de la realidad que estaba opacada en sí misma:

"Se raja, se abre, se desdobla y redobla generando símbolos, máscaras, imágenes, palabras, conceptos, ideas e ideales en los que se hace presente (representándose al tiempo que se institucionaliza) con lo que se establece la diferencia entre lo sagrado y lo profano, lo interior y 
lo exterior, el mensaje y el medio, el sentido y el texto, abriéndose una tensión (insuperable) entre esos dos polos opuestos, "una herida" que está a la base de todo desarrollo o despliegue cultural (es decir, humano)" (Ibid.: 56).

Aquí encontramos un componente esencial: la polaridad se establece en el tiempo y el espacio, entre lo que se denominaría como sagrado y profano, siempre a partir de esa ruptura o herida que se asienta en la realidad.

Para Eliade (1981), la presencia de la realidad se funda desde el momento en que esa ruptura se hace presente en la vida humana a partir del simbolismo y está estrechamente ligado a la existencia de lo sagrado, de esa "realidad por excelencia" (Ibid.: 11). Para este autor, el espacio sagrado es un espacio ontológico, saturado de ser, donde el sujeto que participa en él vive "realmente" (Ibid.).

El espacio sagrado de Eliade, al mostrarse como una entidad plena, real, los otros espacios no son más que formas inconsistentes, profanas, carentes de significación, sin estructura que lo sustente: todo lo que rodea al espacio sagrado es una extensión informe (Ibid.: 15).

La plenitud presente en la revelación del espacio sagrado, posibilita la orientación dentro del mundo profano, caótico. Es a partir del espacio sagrado que se funda un punto fijo, se establece un centro, un eje donde la existencia pueda tomar fuerza, conciencia. Participar de este punto fijo es participar del lugar en donde se puede vivir realmente (Ibid.: 16).

Sea que se defina como un evento que transgrede la realidad o bien como un elemento que se manifiesta como lo único real, lo que nos sugiere el universo simbólico es su capacidad de diferenciarse en el tiempo y el espacio, como una constitución que evoca un contraste, una construcción que va urdiendo sentidos y significaciones en el medio en el que participa, configurando el espacio social y por ende a los sujetos que lo conforman. Lo que muestra es una manifestación "cualitativamente diferente" (Ibid.: 18).

\section{Poder, verticalidad y ascensión en el universo sagrado}

El territorio que se destaca del medio cósmico circundante, aquello que es completamente diferente, verdadero, ha sido expresado por Eliade bajo el término de hierofanía. El autor lo define y contextualiza como la revelación de "un 'punto fijo' absoluto, un 'Centro" (Ibid.: 15).

La revelación de este espacio, de ese centro verdadero que actúa como el fulcro de lo sagrado, adquiere un valor existencial para el sujeto (o los sujetos) que participa de él. Este territorio, esta expresión sagrada, transmite o proporciona una fuente de orientación, poder y trascendencia. Para Eliade "El descubrimiento o la proyección de un punto fijo — el Centro - equivale a la Creación del Mundo" (Ibid.: 15-16).

Toda manifestación de lo sagrado está determinada por lo que Eliade denomina como potencia, entendida ésta como "a la vez realidad, perennidad y eficacia" (Ibid.: 11), tres componentes que demuestran la fuerza del contenido cualitativo en la manifestación de lo sagrado. El término potencia podría bien tener cierta afinidad con el término poder. Según Eliade, esta afinidad se hace presente por el deseo del hombre religioso de adentrarse y participar de la "realidad verdadera", ser en ese espacio diferente, "saturarse de poder" (Ibid.).

De esta manera el espacio sagrado estaría cubierto bajo el manto del poder. Por poder aquí se entendería la capacidad que satura al sujeto por participar de ese lugar distinto que se distingue como una realidad verdadera, ya que este territorio, calificado como real, perenne y eficaz, devela un dimensión que otorga poder al sujeto que se adentra en él, convirtiendo al individuo en un ser cualitativamente diferente.

Para hablar de poder en términos sociales se debe tomar en cuenta la estructura de una sociedad. Implicando la connotación de las relaciones de poder como resultado de las interacciones establecidas por los elementos de un grupo determinado. Estas relaciones de poder responden a un papel preponderante en el universo simbólico, ya que al ser considerado a este 
universo como un ente de comunicación y representación al interior de una cultura, las relaciones de poder lo regularizan y cubren de matices en sus propias expresiones como, por ejemplo, el control mismo de las relaciones de poder. De esta manera puede decirse que las significaciones y sentidos internalizados en el universo simbólico están en constante participación compleja al interior de una sociedad (Elias, 1994: 92).

Tomando en consideración a Elias y a Eliade, el espacio sagrado(el lugar que es cualitativamente diferente, real) representa una región que otorga al sujeto o a los sujetos que se adhieren a él, la potencia, el poder, es decir la capacidad de ejercer, en la esfera social circundante, las funciones correspondientes en las interacciones de jerarquía y por lo tanto a la regularización y control de dichos espacios. Ahora bien, ¿de qué manera se enraíza aún más el aspecto de las relaciones de poder en el contexto teórico que se pretende seguir?

Un elemento importante que Eliade (1981) señala en su estudio simbólico es la noción de verticalidad. Esta noción da cuenta, en primera instancia, de una connotación cósmica en tanto que implica una conexión entre el cielo y la tierra; para Eliade, la noción de verticalidad tiene una carga celestial, su simbología expresa principalmente una comunicación con el Cielo. Según el autor mencionado, "Ningún mundo es posible sin la verticalidad, y esta dimensión, por sí sola, evoca la trascendencia" (Ibid.: 79).

Esta "comunicación con el Cielo" se expresa indiferentemente por cierto número de imágenes relativas en su totalidad al Axis mundi: "pilar (cf. la universalis columna), escala (cf. la escala de Jacob), montaña, árbol, liana, etc.” (Ibid.: 24). Este vínculo revela el sentido de la ascensión donde la verticalidad apunta a poseer o asir el espacio sagrado, el eje cósmico, el centro del mundo.

Para Durand (2005:134), "La ascensión constituye el viaje en sí, el viaje imaginario más real de todos con que sueña la nostalgia innata de la verticalidad pura, del deseo de evasión al sitio híper, o supra, celeste". Esta simbolización de lo alto y por ende de la trascendencia, da lugar a un proceso de agigantamiento o divinización que inspira toda ascensión y altitud. Citando a Bachelard, Durand coloca esta actitud bajo los términos de contemplación monárquica:

"La contemplación de desde lo alto de las cimas da la sensación de un repentino dominio del universo, La sensación de la soberanía acompaña naturalmente los actos y las posturas ascensionales. Lo que hace comprender en parte por qué el Dios celestial es asimilado a un soberano histórico o legendario" (Ibid.: 142).

De esta manera lo sagrado celeste permanece activo a través del simbolismo. La Montaña se presenta entonces como una entidad cósmica: "figura entre las imágenes que expresan el vínculo entre el Cielo y la Tierra; se cree, por tanto, que se halla en el Centro del Mundo" (Eliade, 1981: 25). La montaña "es un símbolo del Universo" (Ibid.: 94), un elemento comunicador entre dimensiones que implican una relación cargada de trascendencia:

"En efecto, en múltiples culturas se nos habla de montañas semejantes, míticas o reales, situadas en el Centro del Mundo: Meru en la India, Haraberezaiti en el Irán, la montaña mítica "Monte de los Países" en Mesopotamia, Gerizim en Palestina, denominada por otra parte "Ombligo de la Tierra". Habida cuenta de que la Montaña sagrada es un Axis mundi que une la Tierra al Cielo, toca al Cielo de algún modo y señala el punto más alto del Mundo, resulta que el territorio que la rodea, y que constituye "nuestro mundo", es tenido por el país más alto" (Ibid.: 25).

Un ejemplo claro es la tradición israelita donde se menciona que Palestina, al ser el país más elevado, no quedó inmerso a causa del Diluvio. O la tradición islámica que considera como el punto más elevado de la tierra al Ká'aba, ya que la estrella polar da testimonio de que se localiza frente al centro del cielo (Ibid.: 25).

Para Eliade, estas creencias dan testimonio de un sentimiento "profundamente religioso: 'nuestro mundo' es una tierra santa porque es el lugar más próximo al Cielo, porque desde aquí, 
desde nuestro país, se puede alcanzar el cielo; nuestro mundo, según eso, es un 'lugar alto" (Ibid.), es decir, la cima de La Montaña Cósmica.

Dentro de este aspecto místico, Eliade nombra varios ejemplos sobre la asimilación de los templos religiosos a las montañas cósmicas, así como su función de comunicar el cielo con la tierra: "los propios nombres de las torres y de los santuarios babilonios dan testimonio: se llaman 'Monte de la Casa', 'Casa del Monte de todas las Tierras', 'Monte de las Tempestades" (1981:26). Otro ejemplo sería el Zigurat, descrita como una montaña cósmica de siete pisos que representaban siete cielos planetarios, al escalarlos el Sacerdote llegaba a la cima del universo. Así también Eliade nombra al templo de Barabudur en Java, edificado como una montaña artificial, escalarlo implica un viaje extático al centro del Mundo donde el peregrino se adentra a una región pura, trascendiendo el mundo profano, contemplando el universo (Ibid.: 27).

Lo elevado es irremediablemente la capacidad de nombrar la trascendencia y la contemplación monárquica. Todas sus formas, encarnadas en una multitud de ritos como la ascensión, la escalada, la cumbre, etc., así como las innumerables construcciones de mitos y leyendas que se describen a su alrededor, develan la significación y la importancia que implica "la imagen ejemplar de la trascendencia" (Ibid.: 79), elemento que hace de centro y eje de la exaltación que confiere el Axis mundi. Por lo tanto, entendida en su generalidad de símbolo, de elemento comunicador entre el cielo y la tierra, La Montaña se ubica como un referente simbólico que valida el ejercicio de poder.

Ahora bien, siendo la montaña un referente donde la subjetividad encuentra el medio para validar la posición de un individuo hacia sí mismo y al medio que lo rodea, ¿no estaría en suposición el término autoridad?

La autoridad estaría implícita en la capacidad que tiene el sujeto de otorgarse un lugar en el Axis mundi, estando en el centro, se vuelve él mismo un centro. El centro por lo tanto es algo que se pretende alcanzar, estar a la altura, una suerte de identidad que marca diferencias entre los demás. Es decir que este centro es, en definitiva, un objeto de deseo.

Las relaciones de poder, que se expresarían de un sujeto a otro, sobre otro, a partir de otro, tienen como fuente este objeto de deseo. El imaginario de la cumbre, o bien de la montaña dentro del universo social de los sujetos ascensionistas, se propone aquí como un referente a partir del cual se accede a cierta forma de gobierno: qué se puede o no hacer en una montaña, cómo comportarse, qué ser o qué conviene ser en ciertas circunstancias.

En este sentido, el espacio sagrado lo que hace es poner en evidencia una configuración donde los sujetos están siempre enfocados a conseguir un lugar donde su ser pueda validarse ante sí mismo y ante los demás como una ascensionista, es decir, la constitución misma de una identidad. Acceder entonces al espacio sagrado de la montaña, tiene como norma el cumplimiento de un ritual, un acto y escenario permeado por acciones que validan una transformación, un cambio de esencia, una identidad. Es allí donde entra el acto de la ascensión.

\section{Ascensión: ¿poder o trascendencia?}

La ascensión a los lugares trascendentes implica riesgos, siendo el más importante, aquel donde entra en juego directo la vida: el peligro de la muerte. ¿Podría la muerte, que está presente dentro de los términos de ascensión, involucrarse dentro de este juego significativo de trascendencia?

Para Garagalza (2009: 95) "Los símbolos tienden a agruparse en torno a esquemas dinámicos formando ciertas "constelaciones", Las cuales "van convergiendo hasta delimitar tres grandes tipos de estructuras: las heroicas (o esquizomorfas), las místicas (o antifrásicas) y las sintéticas (o dramáticas)".

La región heroica, dice Garagalza, tiene como dominio la capacidad de abstracción y distinción, así como al principio de no contradicción. Aquí la imaginación tiene una función polémica, debido a que se apoya sobre la acentuación o exageración de la diferencia entre las 
imágenes contrarias instaurando así una visión dualista. En esta región se afronta la instancia de la temporalidad separando los componentes positivos de los negativos, proyectando los primeros sobre un más allá temporal, quedando los últimos como la significación propia del devenir ( $\underline{\operatorname{Sino}})$ "que está irrevocablemente abocado a la muerte" (Ibid.).

Lo que provoca que, en términos ascensionales, los aspectos positivos de la región heroica se proyecten hacia un más allá temporal que tiene que ver con el impulso de vencer y contraponer la angustia de las tinieblas con los símbolos de la luminosidad. El terror de la caída es compensado por el deseo ascensional que dirige la lucha contra la atracción del abismo, "Se trata, pues, de una huida de este mundo 'impulsada' por el deseo de eternidad.", donde "el mero hecho de figurar un mal (o de representar un peligro, de simbolizar la angustia) es ya un modo de domesticarlo o conjurarlo y encierra un esbozo de eufemización". Y es cuando "el terror ante el abismo se carga", se satura "de fascinación (a vencer)" (Garagalza, 2002: 96).

El resultado de esta fascinación a vencer, es el poder debido a los sentidos inmersos de trascendencia que involucra la ascensión. Lo que simboliza el acto vertical es el deseo de sobrepasar la muerte: "Llegué al cielo, soy inmortal" (Durand, 2005: 133). Pero no se trata solamente del poder, implica también un componente de valor axiomático, tanto desde una perspectiva corporal/sensual como simbólica/mental.

En este sentido, según Durand, los símbolos ascensionales son definidos bajo el término de metáforas axiomáticas, de las cuales convergen los conceptos de verdad, así como los valores elevados que son movidos por las imágenes que representan la ascensión. Son axiomáticas en la medida en que el ser humano sitúa su posición corporal a partir de una estructura dominada por la verticalidad, de manera que es un componente inseparable de su naturaleza y equilibrio corpóreo (Ibid.). Se puede afirmar que el sentido vertical que se expone aquí es tanto un componente cultural como corporal en el ser humano.

Sin embargo, esta expresión corporal también comprendería un componente inmerso que he denominado como pasional. Este elemento, cuya manifestación encuentra su ate en caer en la obsesión por lo perseguido, tendría como consecuencia una confrontación o castigo, entendida a través de la paradoja de Ícaro. Para Garagalza (2002), dicha paradoja se encuentra tejida en la persecución de la trascendencia representada en la figura mítica: "Ícaro quiere volar tan alto que, finalmente sus alas de cera se derriten por el calor del sol” (Ibid.: 96). Según el autor, el predominio absoluto de la región heroica tendría como consecuencia "desembocar en la esquizofrenia" (Ibid.).

Uno de los componentes fundamentales que puede apreciarse en el montañismo es el entrecruzamiento de la búsqueda de trascendencia y poder, se trasciende en la ascensión porque se logra la culminación de una identidad, y la identidad, fijada en la supuesta domesticación de un medio calificado como peligro en potencia, valida la postura del sujeto ante los demás. Accede a su verdad, y esa verdad es utilizada como ejercicio de poder, justamente para diferenciarse de los demás, otros que no logran aún, que no tienen su axioma, su verdad, su espacio real, cualitativamente distinto.

La ascensión en cuanto rito preponderante en el mundo vertical, es el elemento a consagrar; el encuentro ansiado de ese espacio fantástico y heroico, saturándose a sí mismo de las significaciones míticas y místicas que involucra la sacralidad a la que se adentra (o asciende). El diálogo que se establece entre él mismo y la verticalidad da cuenta de la capacidad que el sujeto tiene de enmarcarse en el mundo sagrado, de llenar su cuerpo y alma de ese elemento real verdadero.

En este sentido la montaña es un elemento que existe por fuera del mundo profano, responde a un espacio y tiempo cualitativamente distintos. La imagen de la montaña es esencial, sagrada, trascendental; pero el acceso que involucra viene determinado bajo el sentido de enfrentamiento. Es así que el sujeto, siguiendo a Garagalza (2002), emprende una especie de danza al momento de adentrarse y enfrentarse a ese espacio-tiempo, es decir, abriendo la posibilidad de lo que Kerényi denomina con el término de "fiesta" (Ibid.: 117). 
Esta fiesta puede ser vista como una Titanomaquia, enfrentamiento con el titán en griego, que para el caso que nos compete, bien podría ser un enfrentamiento con la montaña (mismo que proporcionará trascendencia). Encontramos entonces una dicotomía en el sentido simbólico asignado a la montaña, representado por la imagen sagrada y la lucha por la trascendencia que involucra la ascensión, dicotomía necesaria para adentrarse al espacio diferente, cósmico:

\begin{abstract}
"A diferencia del arte que, según nuestro autor, fija en la realidad captada la atmósfera del instante creador arrancándolo del tiempo, perpetuándolo, la fiesta no se eleva a esa altura intemporal, a la eternidad de lo clásico, sino que sigue en contacto con el tiempo aunque se destaca de él por el realzamiento de los cortes que lo dividen en fases: "Éstas, en cuanto son fases del tiempo, tienen su aspecto temporal, pero como son fases significan también, por así decirlo, un detenerse el tiempo, un detenerse no en el sentido místico sino en el sentido espiritual. No como eternidad (...), sino como un punto donde se hace patente la presencia de figuras espirituales fuera de todo 'donde' y de todo "cuando" (Ibid.: 118).
\end{abstract}

Este instante ampliado, conjurado, ritmado o conjugado, da cuerpo y sustento al tiempo propio de la fiesta: "Surja donde surja, donde quiera que se la vuelva a conjurar, la fiesta trae consigo siempre ese carácter inmediato y sugestivo, que convierte al mismo tiempo en un instante creador" (Ibid.: 118-119).

Instantes de originalidad, calor y frescura, que hacen ver al tiempo ordinario como un espacio perecedero. Estos son instantes que elevan y se elevan: "El etnólogo se encuentra en todas partes del mundo estos tiempos transformados - 'tiempos elevados', donde "La vida les da su calor y están impregnados de ideas sugestivas. Se pondrá de manifiesto que en ellos tampoco falta lo creador. A estos tiempos se los llama fiestas" (Ibid.: 119).

El tiempo festivo se establece como región determinada del tiempo "en la que se hace posible captar aquello 'que solo se hace presente en el instante', como una zona o un lugar que se destaca de la geografía del tiempo, sin desconectarse de ella, (...) elevarse en la vertical sin abandonar la tierra" (Ibid.). De esta manera el tiempo festivo se establecería como un tiempo sagrado, es decir, la fiesta es sagrada en tanto que su manifestación responde a una irrupción en el tiempo, consagrándose como un lugar, una región cualitativamente distinta.

Para un mayor énfasis del fondo expresivo representado por esta región, Garagalza muestra "la concepción del tiempo festivo (...) mediante la imagen de la montaña, del muro de piedra que se abisma en lo alto" (Ibid.), reflejada en la traducción de los siguientes versos:
"Montaña/// Eres el lugar en el que la Tierra / se desborda en el Cielo. // Tu cima, / lo inhabitable, / es lugar sagrado: / en ti coinciden / lo Alto y lo Bajo. // Contracción de la llanura / en ladera, / sólo en la Piedra, / el más pesado vástago en la Tierra, / soportas el abismamiento / hacia las alturas. // Piedra pesada / disfrazada de blancura, / perduras, / sin desprendimiento, / allí donde el aire volátil / se enrarece. // Pesantez suprema, / símbolo de separación / sin abandono / de la Tierra. // Trascendencia inmanente, / permites al hombre / el vuelo sin alas, / danzar a tu son / en lo vertical, / penetrar en el Cielo / sin despegar de la Tierra" (Ibid.: 119-120).

Para Garagalza, la montaña hace posible el alpinismo, al que define como "una actividad en sí misma tan absurda como los movimientos del torero cuando se hace abstracción del movimiento del toro" (Ibid.). Es así que en el alpinismo:

\footnotetext{
"La ley de la gravedad queda condicionalmente suspendida, una condicionalidad que se patentiza cuando el escalador no se ajusta a sus límites o se equivoca o cuando el tiempo y la montaña no se encuentran benignos. No se trata pues de una superación sino más bien de una especie de tauromaquia de la gravedad mediante una danza en la vertical, al son de la piedra" (Ibid.).
} 


\section{La ascensión a la cumbre, ¿un juego profundo?}

Según el Diccionario de la Real Academia de la Lengua Española, la palabra cumbre viene del latín culmen que significa "cima o parte superior de un monte o bien mayor elevación de algo o último grado a que puede llegar" 2 . En este sentido, cumbre se emplea como un término que representa un status en calidad de logro, utilizado en cualquier actividad que pueda emprenderse. Es así que dicho término proporciona un imaginario de meta u objetivo específico que se ancla en expresiones como alcanzar, lograr, llegar, cumplir, conquistar.

En su acepción clásica, la palabra ascensionismo refiere los propósitos de individuos determinados que se proponen asir la cumbre de una montaña; en cierto sentido, se puede decir, de amparar el fondo obsesivo, mágico, etéreo de posarse por un instante en ese espacio inhabitable que marca el punto más alto de una superficie y que se ha nombrado bajo los términos de cumbre, cima, cúspide.

Han sido numerosas las ocasiones en que se ha visto, presenciado o escuchado laurear a quien ha conquistado una montaña. Todo lo que se pueda asemejar al término cumbre, corresponde a un juego de apelativos o expresiones que denominan la importancia de aferrarse a un lugar delineado, atravesado, consumado de trascendencia. La justificación principal, como se ha puesto en énfasis (la posesión de la cumbre), es llegar a decir que "se ha subido una montaña": se ha logrado algo en particular, se ha colmado un desafío que casi siempre termina con ansias de más y más cumbres.

Reinhold Messner -primer ser humano en coronar la cumbre del Everest sin oxígeno y primero en completar los 14 ochomiles-, en su libro "La zona de la muerte", apelativo éste que se utiliza para nombrar el límite de la vida sin oxígeno artificial a los 8000 metros de altura, expresa en su primer capítulo:

“Escalar montañas, ¿una adicción?” lo siguiente: “Hoy sé que el ser humano no es algo indestructible, sino más bien un proceso, una circunstancia cambiante. Le tengo a la vida tan poco miedo como a la muerte, y quiero estar tan poco constreñido como me sea posible, (...). Yo no sólo quería incluir estas cumbres en mi lista de itinerarios, sino también tener una experiencia de mí mismo ahí arriba y conocerme todavía mejor. Para mí, el alpinismo no es, al menos de un modo primario, una huída de las insoportables condiciones de la sociedad industrial occidental. El alpinismo significa vivir para mí mismo, vivir en el sentido de la expresión de uno mismo, del Ser. (...) El ámbito místico -la cumbre está arriba, es Dios- no me interesa. Entonces ¿qué es lo que hace que el terreno fronterizo de la zona de la muerte sea tan importante? La experiencia vital del final, extraída de la propia muerte, y el sentimiento que a veces se experimenta de abrazarse al mundo" (Messner: 2001:25. Énfasis añadido).

En el ascensionismo se encuentran diversos puntos que definen o autodefinen al montañismo. Este ejercicio epistémico de conceptualización del significado, tiene como objetivo esclarecer y categorizar las definiciones que se dan a la hora de establecer un enunciado sobre lo que es el ascensionismo de montaña. Estas manifestaciones, en su gran mayoría, han sido escenario de reflexión por parte de los principales protagonistas de la historia del montañismo mundial ${ }^{3}$. Los términos que rodean o sigilan estas definiciones son juicios o valoraciones cercanas a lo que se denominaría como un ir más allá. Dichos términos, o más bien algunos de ellos, están marcados con aspectos pasionales como: obsesión, aventura, eternidad, enfrentamiento, libertad,

2 Disponible en: http://buscon.rae.es/draeI/SrvltConsulta?TIPO_BUS=3\&LEMA=cumbre. Visitado el 20 de enero de 2013.

3 Ejemplos como "Los conquistadores de lo inútil”" de Lionel Terray, "Montañas de una vida" de Walter Bonatti, "The cristal horizon, Everest: the first solo ascent" de Rinhold Messner, "Mi mundo vertical" de Jerzi Kukutzcka, entre muchos otros, realzan esta intensa búsqueda y proliferación de las definiciones que surgen sobre el montañismo. Todos ellos han sido considerados como personajes insignes del alpinismo por haber desplazado la línea imaginaria entre lo posible e imposible, los límites del cuerpo humano, los lugares inaccesibles, etc. Esto, cómo se verá a lo largo de la presente tesis, delineará la pauta y solfeo de la práctica del alpinismo a un nivel universal. 
experiencia vital, entre muchos otros y en su gran colectividad asociados a la imagen de una montaña o cumbre.

El sentido utópico o ideal, predomina en las construcciones de sentidos al momento de definir el montañismo, siempre recayendo en un aspecto de lejanía, majestuosidad y pureza, tal y como se lo identifica en la siguiente frase: "lo desconocido y lo misterioso es lo que lanza al hombre a conquistar las cimas. ¿Cuántas veces no se ha sentido obsesionado con la idea de alcanzar una meta y no descansa hasta que logra por fin realizar su sueño?" (Gaviria, 1982: 12)

El libro Montañismo, La Libertad de las Cimas (con más de 600 páginas sobre normas y técnicas, utilizado u ojeado por muchos andinistas en Ecuador, además de ser el libro base en las bibliotecas de los principales clubes de andinismo de este país) inicia su discurso con la siguiente definición:
“Algo más que escalar, disfrutar de vistas panorámicas o vivir una experiencia al aire libre; también comporta desafío, riesgo y privaciones. Y no es una actividad para cualquiera. Quienes se sientan atraídos por las montañas pueden encontrarlas tan emocionantes e irresistibles como frustrantes, y a veces incluso mortales. Hay cualidades en el montañismo que aúnan el entusiasmo y la alegría en una actividad que es más que un pasatiempo, más que un deporte: una pasión, sin duda, y a veces una obsesión" (Graydon y Hanson, 2001: 15).

Continuando dicho párrafo le siguen algunas reflexiones de personajes importantes de este mundo vertical:

\begin{abstract}
“¿Qué fuerza es la que me empuja?”, se pregunta el alpinista americano Fred Beckey. "Algo complejo e indefinible, la atracción de lo incierto". Algunos años antes, el escalador británico George Leigh Mallory, ofrecía otra versión de la atracción por las montañas: "Lo que obtenemos con esta aventura es pura diversión" (Ibid.).
\end{abstract}

La introducción del libro concluye su discurso sellando al montañismo bajo la definición de sufrimiento: "Escalar montañas es una forma incómoda de pasar el tiempo libre, y cualquiera que lo haya hecho sabe lo que quiso decir el escalador polaco Voytek Kurtyka con su expresión: "El alpinismo es el arte del sufrimiento" (Ibid.).

Sherry Ortner en su ensayo Resistencia densa: muerte y construcción cultural de agencia en el montañismo himalayo, cobija al montañismo bajo los términos de juego profundo. Este enunciado fue formulado por Clifford Geertz (2003) a partir de un concepto de Bentham, quien utiliza dicha expresión para designar "el juego en el cual lo que se arriesga es tanto que, desde el punto de vista utilitario, es irracional que los hombres se lancen a semejante juego" (Ibid.: 355). Geertz lo explica de la siguiente manera:

"Si un hombre cuya fortuna alcanza a mil libras (o ringgits) apuesta quinientas en una parada igual, la utilidad marginal de las libras que se propone ganar es claramente menor que la inconveniencia de lo que arriesga perder. En el genuino juego profundo, ésta es la situación de ambas partes. Una situación temeraria. Se reunieron en busca de un momento agradable y entraron en una relación que deparará a los participantes sufrimiento antes que placer" (Ibid.: 335).

Para Geertz las personas están involucrándose constantemente en formas de juego profundo debido a que éste "compensa a sus practicantes en términos de la producción de sentido, de la penetración en dimensiones importantes de vida y experiencia” (Ortner, 1999: 6).

¿Por qué subir montañas? ¿Qué hay con entrar a un mundo frío e incontrolable? En soporte a la asociación entre juego profundo y montañismo, Ortner hace reseña de una abundante literatura autobiográfica donde los escaladores y montañistas relatan los diversos sentidos y discernimientos que reciben de este deporte: "escriben sobre la fibra moral del yo interno, (...), sobre la calma y la paz de las frías alturas contra el ruido y el alboroto de la sociedad moderna" 
(Ibid.: 7). Para Ortner todo esto hace que el riesgo de accidente y bien la exposición de muerte valga la pena: "de hecho, parece que es justamente el riesgo de accidentes graves o fatales aquello que produce la recompensa de sentido" (Ibid.).

Para explicar esta relación entre la muerte y la construcción de sentido en el montañismo, Ortner cita un párrafo del libro $\underline{\text { Risk }}$ de Thompson, en el cual se pone como base al riesgo en el momento de puntualizar lo que éste denomina como estética del montañismo del alto nivel. En dicha cita expresa:

"Si [la muerte es] producida correctamente (durante un ascenso, un descenso o en un vivac), borrarse de la lista de los vivos confiere gloria alrededor: para los muertos por probar su voluntad de escalar, para la montaña por el nuevo respeto que demanda y para los sobrevivientes por el coraje de continuar frente al desastre. A diferencia de cualquier otro deporte, el montañismo requiere que sus jugadores mueran" (Barcott, 1996 en Ortner, 1999: 7).

Mariana Landázuri (1989), en su artículo ¿Por qué subir montañas?, dedicado al montañista Ramiro Navarrete -considerado como el mayor exponente del montañismo en la historia del andinismo ecuatoriano- ampara su discurso bajo las concepciones personales del propio Navarrete:

"Y como para sepultar desde el principio cualquier impresión idealizada del ascensionismo, enfatiza: "He ido desechando una serie de ideas románticas alrededor de esto, por ejemplo eso de que el contacto con la naturaleza le vuelve al hombre más puro, menos apegado a las cosas de este mundo o le acerca más a Dios. Para mí todo eso es mentira. Lo que uno encuentra en la montaña se basa en lo que uno lleva desde abajo. No es que una persona sea mejor porque suba montañas; en los montañeros se encuentran los mismos defectos de la gente en todas partes" (Ibid.: 24).

La enunciación que finalmente da Navarrete concuerda con el sentido de juego, pero un juego de autodeterminación, de autodominio, donde el sujeto se ve suspendido en un espacio que lo va forjando, acercándose a sus propios abismos a la vez que se encuentra ante el vacío de la montaña, como reflejando un lugar interior y agresivo: mirarse a sí mismo, cercándose a sí mismo4:

"Yo cada vez lo asocio más a la niñez, para mí subir a las montañas es como un juego; tal vez en eso radica lo grandioso. Si algo diferencia al hombre de los otros seres, es la capacidad (...) de no aceptar al mundo como una cosa ya hecha, sino de poder cambiarlo, y eso creo que es el juego. Me gusta ascender porque siento el placer que siente un niño creándose su mundo al jugar, eso es lo que yo hago, creo mi mundo, lo determino, soy el que dicto las reglas y me pongo los retos. En definitiva uno se va conociendo a sí mismo; la lucha, más que con la montaña es con uno mismo, la montaña no es más que el escenario, en otras circunstancias habría podido ser el mar" (Ibid.: 24).

En dicha definición hay un componente importante de identificación general: el hombre, lo humano. Éste en su juego de la cultura, poseedor de la capacidad de cambiar y modificar su ecosistema, de llevar consigo esa extensión de lo material a todos los rincones que se propone ir. Aquí se hace evidente una transición tajante que deja de lado a la experiencia de lo sagrado y trascendental por una visión de transformación y dominación de la naturaleza. O quizá algo más.

¿Podría ser el juego profundo del montañismo una ilusión? Tomando en consideración que la cumbre, la cima -como para ir lo suficientemente lejos en ese ser extraño- es un lugar inhabitable, nadie puede permanecer más de 48 horas en un lugar como éste sin sufrir graves

4 Este tipo de discurso concuerda con la cita de Reinhold Messner. Se adopta en ambas posturas una inclinación personal, individual de, podría decirse, autoconocimiento y autodeterminación. El sujeto en este sentido divaga en lo que son las reflexiones que se tornan hacia sí mismo, dando así un reflejo de la montaña en el individuo y viceversa. 
daños en el organismo. Bajo este aspecto ¿no representaría el andinismo la obsesión por dominar lo inconquistable? ¿No sería el juego profundo un juego de ilusiones? ¿No sería la montaña la expresión más fiel de lo humano por controlar esa pulsión de superar la sensación de pequeñez, insuficiencia que le despierta al estar frente a un horizonte vasto, casi incomprensible?, ¿no sería acaso el montañismo la evidencia más palpable de que el ser humano, la cultura, su imaginario se configuran a partir del enfrentamiento con el todo que termina siempre por desbordarse a pesar de todo el esfuerzo que empeñe en contextualizarlo, delimitarlo, asegurar sus sentidos?

La riqueza del montañismo está en el flujo simbólico, corporal, pasional que evidencia la profundidad de su ser. A pesar de ser o aparecer como inentendible, o los absurdos de un aspecto turístico o snob deportivo, es un horizonte complejo, incluso si el esfuerzo por realizar un estudio sobre aquello resulte ilusorio.

\section{Bibliografía}

Alexander, Caroline. 2006, "Venciendo lo imposible", en: National Geographic, noviembre, pp. 40-65.

Augé, Marc. 1987, Símbolo, función, historia, Grijalbo, México.

Barthes, Roland. 1989, La cámara lúcida, Paidós, Barcelona.

Cañete, Miriam. 2010, "El modelo triádico de Gerard Genette", en: http://entretextosteorialiteraria.blogspot. $\mathrm{com} / \mathrm{search}$ ?updated-min $=2010-01-01 \mathrm{~T} 00: 00: 00-08: 00 \& u p d a t e d-\max =2011-01-01 \mathrm{~T} 00: 00: 00-08: 00 \& \max -$ results $=3$, visitado el 4 de febrero de 2012.

Durand, Gilbert. 2005, Las estructuras antropológicas del imaginario, segunda parte, F.C.E, España.

Eliade, Mircea. 1981, Lo sagrado y lo profano, en: http://historiaiuna.com.ar/wp-content/material/2013_libro eliade_lo-sagrado-y-lo-profano.pdf .

Elias, Norbert. 1994, Teoría del símbolo, Península, Barcelona.

Geertz, Clifford. 2003, La interpretación de las culturas, Gedisa, Barcelona.

1997, "Ethos, visión del mundo y análisis de los símbolos sagrados", en: Moreno Yánez, Segundo y Marco Vinicio Rueda, Cosmos, hombre y sacralidad, Abya-Yala, Quito, pp. 91-112.

Graydon, Don y Hanson, Kurt. 2001, Montañismo, la libertad de la cimas, Desnivel, Madrid.

KERÉNYI, K. Citado por GARAGALZA, Luis. En: Introducción a la hermenéutica contemporánea, Páginas 116-119.

Kukutzcka, Jerzi. 2010, Mi mundo vertical, Desnivel, Madrid.

Landázuri, Freddy. 1988, "Sisha Pagma, primer ochomil ecuatoriano", en: Revista Campo Abierto, n 11, pp. 8-14.

Landázuri, Mariana. 1989, “¿Por qué escalar montañas?”, en: Revista Campo Abierto, n¹2, pp. 23-26.

Martí, Jordi. S/F, "El excursionismo: entre la ciencia y la estética", en: http://www.ub.edu/geocrit/sv-23.htm, visitado el 13 de abril de 2013.

Messner, Reinhold. 2001, La zona de la muerte, terreno fronterizo, Desnivel, Colonia.

1989, The crystal horizon, Everest: the first solo ascent, The Mountaineers, Seattle.

Nichols, Bill. 1997, La representación de la realidad, Paidós, Barcelona.

Ortner, Sherry. 1999, "Resistencia densa: Muerte y construcción cultural de agencia en el montañismo himalayo", en: tttp://www.idaes.edu.ar/papelesdetrabajo/paginas/Documentos/05_13_OrtnerResistenciadensa.pdf , visitado en mayo de 2011.

Pleyán, Carmen. 1974, "Teoría y técnica de la literatura", en: Enciclopedia Labor, Tomo VII, Labor, Barcelona, pp.1-44.

Rosaldo, Renato. 2000, Cultura y Verdad, Abya-Yala, Quito.

Rueda, Marco V. 1993, Mitología, PUCE, Quito.

Villafañe, Justo. 1998, Introducción a la teoría de la imagen, Pirámide, Madrid. 